\title{
Diurnal evolution of water flow and potential in an individual spruce: experimental and theoretical study
}

\author{
P. Cruiziat ${ }^{1}$, A. Granier ${ }^{2}$, J.P. Claustres ${ }^{1}$ and D. Lachaize ${ }^{1}$ \\ 1 Laboratoire de Bioclimatologie, INRA, Domaine-de-Crouelle, F-63039 Clermont-Ferrand, and \\ 2 CRF de Nancy, INRA, Station de Sylviculture, BP 35, F-54280 Seichamps, France
}

\section{Introduction}

We present a model built primarily to study the water flow in a single tree within a forest. After comparing it with other available systems, we develop the characteristics of our model and its usefulness.

\section{Materials and Methods}

\section{Outline of the model}

The structure of the model (Fig. 1) comes from our idea of how the spruce we work with is compartmented; 7 compartments were distinguished: leaves (1), uppercrown (2), lower crown (2), trunk (2). Except for leaves, 2 kinds of water reservoirs constitute each of the 3 preceding levels (Jarvis, 1975; Granier, 1987; Granier and Claustres, 1989): a small one corresponding to the elastic tissues with a small constant of time and a larger one representing the sapwood with a large time constant. Twelve resistances must be specified. Although SPICE, the circuit simulation program we used, allows us to introduce variable capacitances and resistances (Cruiziat and Thomas, 1988), we did not think they were necessary at this stage of our experimental knowledge.

\begin{abstract}
Assumptions
1. Sap moves from points of high potential to points of low potential. 2. Flow within the different parts of the system obeys the Darcy equation. 3. Roots are not supposed to have a capacitance (optional). 4. All parameters are lumped together. 5. Neither branch, twig architecture nor growth are considered (optional).
\end{abstract}

\section{Values of the parameters and input variables}

The data consist of hourly measurements of sap flow (bottom of the trunk), leaf water potential at 2 levels and transpiration rate per tree (calculated by the Penman-Monteith equation for the stand). In addition, sapwood cross sectional area and dimensional characteristics at different levels provide information for starting values of the parameters (resistances and capacitances). Then they were adjusted (by trial and error) in order to obtain a combination of values which reasonably fit our measurements.

\section{Properties}

Under 'ideal' conditions (regular transpiration, all potentials, including $\psi_{\text {soil }}$ starting at $0 \mathrm{MPa}$ ), there is a continuous evolution of $\psi$ in the different parts of the tree (Fig. 2); only the reservoirs from elastic tissues show no residual deficit at the end of the night; the sapwood tissue still stays at a negative $\psi$, its contribution is about $3 \%$ of the daily transpiration. This 


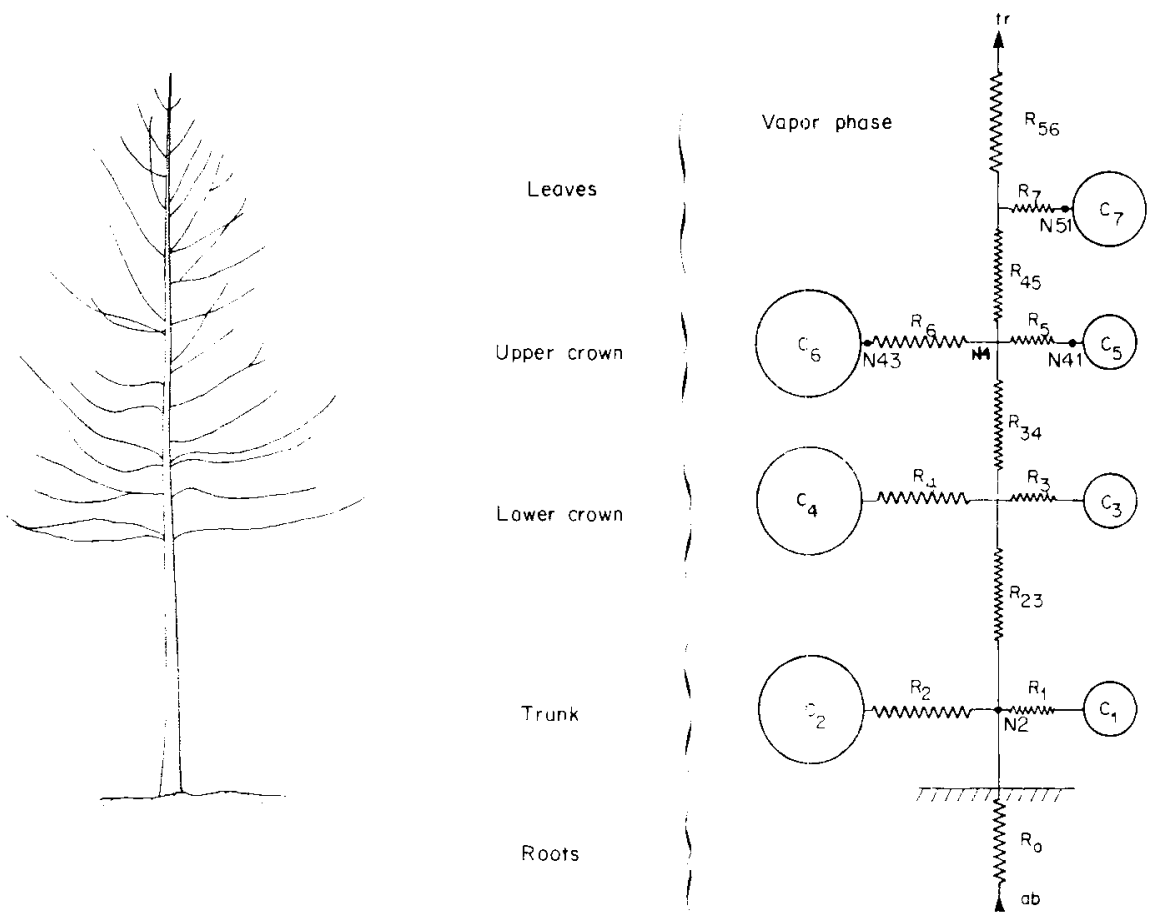

Fig. 1. The working model of water movement in a Picea abies tree within a stand. It is made of 7 reservoirs $\left(C_{1}-C_{7}\right)$ and 12 resistances: $C_{1}, C_{3}$ and $C_{5}$, represent the reservoirs of elastic tissues; $C_{2}, C_{4}$ and $C_{6}$, those of the sapwood at 3 different levels in the trunk. $\mathrm{C}_{7}$ is the leaf reservoir. Values of these parameters constitute the inputs together with transpiration and soil water potential. The simulation gives flow and potentials at different nodes.

proportion increases gradually if the $\psi_{\text {soil }}$ falls for several days.

The difference between maximum rates of transpiration $\left(E_{\max }\right)$ and absorption is greatly affected by the relative magnitude of root resistance.

The minimum value of $\psi_{\text {leaves }}$ occurs leaves about $1 \mathrm{~h}$ after $\left(E_{\max }\right)$ : at that fime, transpiration and absorption are equal. This fact provides a means to obtain an estimation of the total resistance of the transpirational pathway (Fig. 3).

It is possible to determine the 3 parameters (2 resistances and 1 capacitance) of the equivalent circuit having the same transfer function (= transpiration versus absorption). This transformation allows those interested in water balance of drainage basins to use this simplified version as a subrnodel.

\section{Discussion and Conclusions}

This model was designed to be a working tool. It has 2 main purposes: 1) to continuously bring together new experimental data within a coherent representation; and 2) to help us to select the most crucial measurements. Our model differs from 


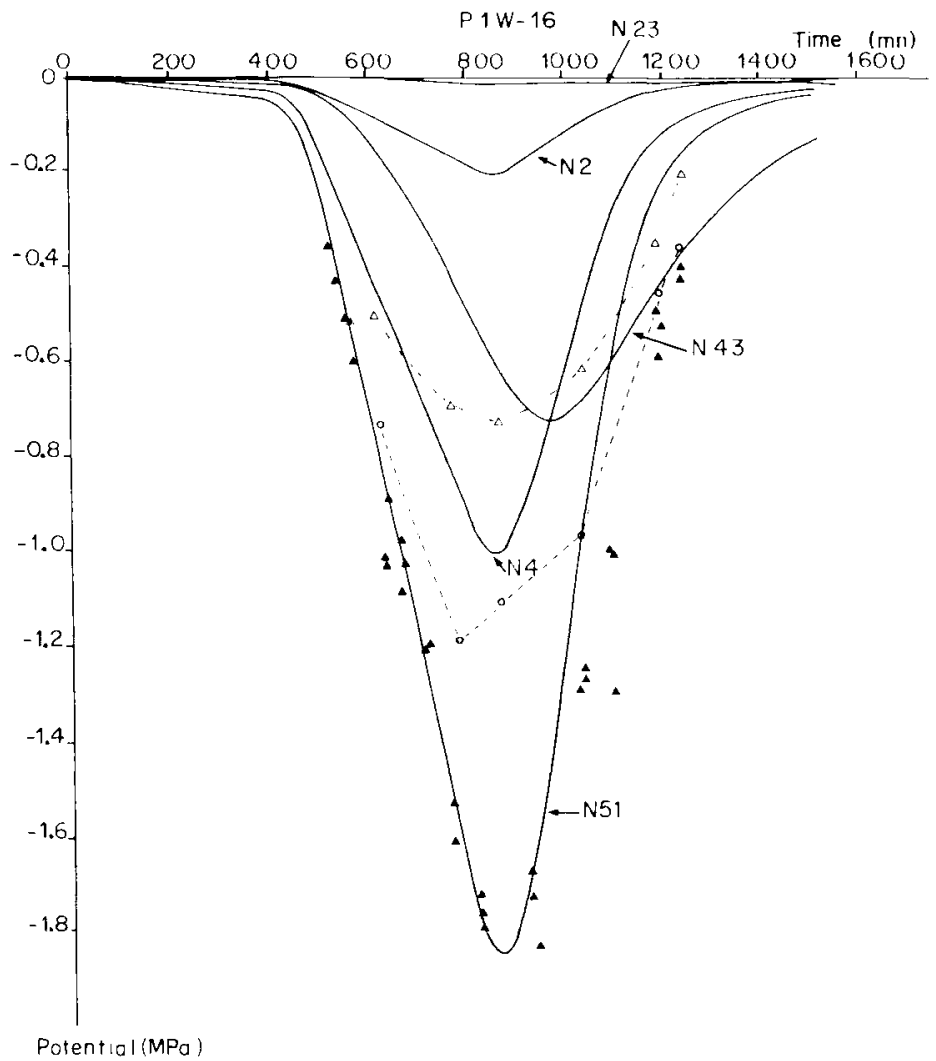

Fig. 2. Real and simulated water potential (same tree as Figs. 1 and 3 ). $N_{2}-N_{51}$ refer to nodes as indicated in Fig. 1. A-A: water potential data of twigs from the upper crown; water potential of non-transpiring bagged leaves from upper $(0--0)$ or lower $(\Delta--\Delta)$ crown.

other published models (Landsberg et al., 1976; Milne and Young, 1985; Wronski et al., 1985; Edward et al., 1986) by its structure. Nevertheless, for the moment, due to the lack of experimental data, it is likely that several models of the same object (e.g., same species) can be presented, each having its own strengths and weaknesses. Therefore, we believe that it is more useful to compare different approaches to the same object rather than different models designed for different objects.

\section{References}

Cruiziat P. \& Thomas R. (1988) SPICE, a circuit simulation program for physiologists. Agronomie 8, 49-60

Edwards W.R.N., Jarvis P.G., Landsberg J.J. \& Talbot H. (1986) A dynamic model for studying 


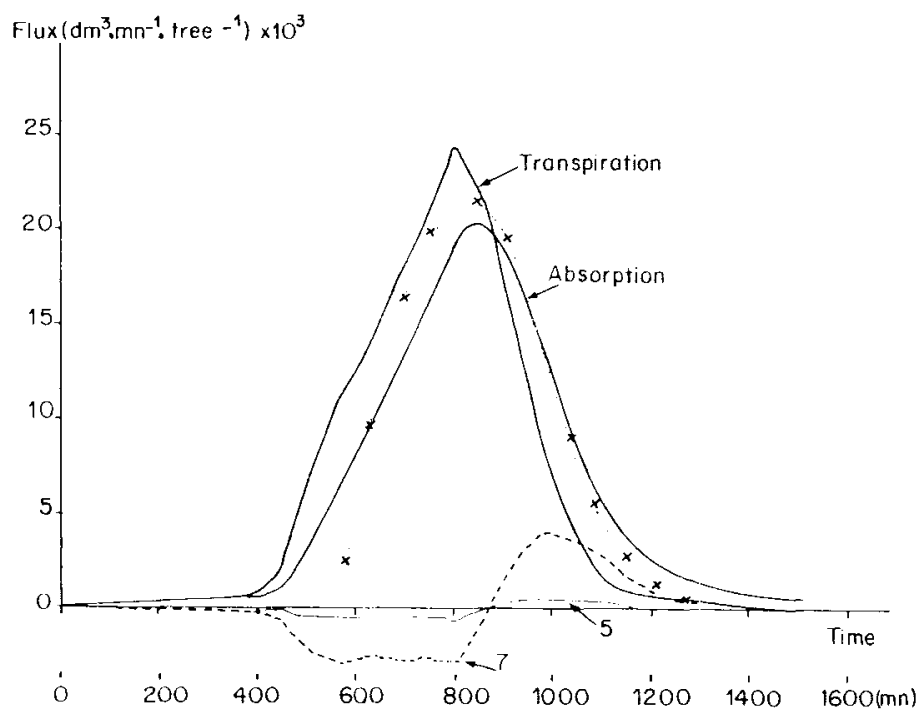

Fig. 3. Real and simulated water flow in the trunk during a day for a Picea tree within a stand. Transpiration is an input variable, absorption and flow 5 and 7 are simulated; 7 refers to the flow of the leaves and 5 refers to the flow from elastic tissues in the upper crown. The dotted line represents the measured flow at the bottom of the trunk.

flow of water in single trees. Tree Physiol. 1, 309-324

Granier A. (1987) Mesure du flux de sève brute dans le tronc du Douglas par une nouvelle méthode thermique. Ann. Sci. For. 44, 1-14

Granier A. \& Claustres J.P. (1989) Relations hydriques dans un épicéa (Picea abies L.) en conditions naturelles: variations spatiales. Oecol. Plant. 2, in press

Jarvis P. (1975) Water transfer in plants. In: Heat and Mass Transfer in the Biosphere. Part 1. Transfer Processes in Plant Environment. (de
Vries D.A. \& Afgan N.H., eds.), John Wiley \& Sons, New York, pp. 369-394

Landsberg J.J., Elanchard T.W. \& Warrit B. (1976) Studies on the movement of water through apple trees. J. Exp. Bot. 27, 579-596

Milne R. \& Young P. (1985) Modelling of water movement in trees. In: IFAC Identification and System Parameter Estimation, York, U.K., pp. 463-468

Wronsky E.B., Holmes J.W. \& Turner N.C. (1985) Phase and amplitude relations between transpiration, water potential and stem shrinkage. Plant Cell Environ. 8, 613-622 